Rodrigo Andrés Tovar

rodrigotovme@gmail.com

Universidad de Salamanca

(Recibido: 29 mayo 2020/ Received: 29th May 2020) (Aceptado: 23 septiembre 2020 / Accepted: $23^{\text {rd }}$ September 2020)

\section{RODARI Y CEBOLLÍN. HÉROES DE UNA REVOLUCIÓN}

RODARI AND CIPOLLINO. HEROES OFA REVOLUTION

\title{
Resumen
}

El presente artículo expone una brevísima reseña biográfica de la juventud del autor italiano Gianni Rodari. Se hace énfasis en los datos que forjaron su labor como escritor para niños y en aquellos que guiaron sus intereses políticos: su vida durante las dos décadas de concierto fascista en Italia, su militancia en el Partido Comunista italiano, su labor como periodista y dirigente tanto de publicaciones como de grupos juveniles y, finalmente, los hechos que lo llevaron a escribir para niños. Para esto, se han tenido en cuenta las circunstancias biográficas que lo formaron como persona y las que, de cualquier manera, influyeron en la formación de su pensamiento y en sus elecciones profesionales. Por último, se habla de su primera obra La novela de Cebollín (1951) como condensación de la posible visión política y social de Rodari en esta primera etapa de vida profesional.

Palabras clave: Literatura infantil; Pensamiento; Rodari; Cebollín.

\begin{abstract}
This article presents a very brief biographical review of the Italian author Gianni Rodari's youth. Emphasis is placed on the data that shaped his work as a writer for children and guided his political interests: his life during the two decades of fascism in Italy; his membership in the Italian Communist Party; his work as a journalist and head of publications and associations; and, finally, the facts that made him write for children. Thus, the biographical circumstances that shaped him as a person, and those that influenced his thought and his professional choices have been considered. Finally, his first work II romanzo di Cipollino 'The novel of Cipollino' (1951), is briefly shown as a summary of Rodari's possible political and social vision in this first period of his professional life.
\end{abstract}

Keywords: Children's literature; Thought; Rodari; Cipollino.

\section{Introducción}

Un mensaje claro y casi imperturbable en el tiempo es posible desde que el ser humano inventó el código escrito. En consecuencia, no es de sorprender que la literatura, la prensa y, entre 
otros, el texto escolar, se hayan usado como medios idóneos mediante los cuales se han hecho circular pensamientos e ideas. Los "textos sagrados" de cualquier religión pueden ser ejemplos diáfanos de cómo perpetuar un propósito doctrinal usando la escritura como herramienta para inculcar una ideología que trascienda el tiempo.

Asimismo, los mitos y leyendas que las culturas primitivas crearon para darle una razón a su estancia en el planeta, tomados como la manera más arcaica de entender el mundo con empirismo y fantasía, fueron conscientemente concebidos para el raciocinio general de los adultos; estos, a su vez, los iban propagando también en sus comunidades infantiles para prolongar las creencias de lo tradicional. Entonces, la mente y la fantasia humana "se fueron poblando de seres similares a los humanos, pero más grandes y potentes, personificando los elementos y los fenómenos, para atribuir a ellos causas y efectos de todo lo que el hombre primitivo no era capaz de explicarse" (Tivaldi, 1970: 5)'.

Gracias a esta dinámica, surgen dos fenómenos culturales importantes para la historia del ser humano. Por una parte, se comprende que, a través de la narración, primero oral, más tarde escrita, se puede influenciar el pensamiento colectivo; por otra, aquellas remotas creaciones de la fantasía humana, las primeras leyendas y los primeros mitos que se transmitían de persona a persona, de generación en generación, tal vez iniciaron lo que hoy se entiende como literatura infantil, pues, sin duda, dichas historias fabulosas e imaginativas constituyeron el primer patrimonio literario para niños.

A partir de esto, se deduce que la tradición de llevar una enseñanza a la población general por medio de la literatura es tan antigua como la literatura misma y, como lo ha demostrado la historia, los niños han sido el blanco predilecto de dichas instrucciones. Por esta razón, incluso hoy en día, es tan común asociar la literatura infantil con la pedagogía, pues se cree que los niños leen únicamente para aprender. Entonces, no ha de sorprender que muchos escritores para niños, sobre todo aquellos que lo han hecho por encargo, incluyan una moraleja textual, directa y edificante dentro de su cuento.

Tal es el caso de los famosos cuentos de hadas expuestos por autores como Charles Perrault o los Hermanos Grimm, quienes, a través de fábulas simbólicas adaptadas de la tradición oral, acercaban los preceptos morales de la época a los niños. De la misma manera, las fábulas del griego Esopo, con su ingenio y jovialidad, a través de un sano humor y un equilibrio audaz entre malicia y moralidad, constituyeron, hace más de dos mil quinientos años, una fuente literaria que manifestaba la sabiduría popular.

En general, los ejemplos se extienden a lo largo y ancho del planeta y del tiempo. En el caso específico de la literatura infantil italiana, uno de los modelos clásicos es el libro del napolitano Giambattista Basile: Lo cunto de li cunti 'El cuento de los cuentos', escrito en dialecto y publicado en Nápoles en 1636. Si bien es una obra estrictamente dirigida al público adulto por la complejidad de los temas tratados, el tono narrativo y la cercanía al mundo de lo popular hicieron que, como es costumbre en situaciones similares, el libro ganara la atención de los niños.

También, la obra Pinocho, historia de una marioneta, publicada en volumen por primera vez en 1883, recrea las aventuras de un "muñeco de madera» con todos los atributos de un niño, es decir, un objeto inerte humanizado, a quien suceden diversas situaciones que le hacen reflexionar y aprender múltiples lecciones. Por esta razón, se considera que Pinocho es el claro ejemplo del «niño» que aprende a ser adulto. Como se expresa en Cambi (1985: 72), "Pinocho representa una idea de

1 Todas las citas procedentes de textos en italiano, como los extractos de las obras literarias italianas, han sido tomadas de las ediciones originales y traducidas al castellano por el propio autor del presente trabajo. 
infancia, una niñez que necesita ser incentivada y formada para el progreso nacional", esto reafirma la idea de una literatura infantil que expone y delimita una visión de niñez particular (Tovar Méndez, 2017).

Teniendo en cuenta lo anterior, se ha querido observar la forma en que han surgido, en la mitad del siglo XX, los textos del italiano Gianni Rodari, quien en sus primeros escritos introduce un pensamiento personal sobre el momento histórico que vive y expone su ideal de sociedad, ya que, sus obras "se nutren de la fuerza disruptiva de la cultura laica, progresista, marxista que descubría y animaba la realidad nueva de la Italia democrática" (Argilli, 1970).

Por otra parte, Rodari evitó conscientemente caer en el tono paternalista, manipulador, lacrimógeno y estrictamente edificante en el que gran parte de la literatura de la época estaba estancada. Además, en el escritor, de quien se debe tener en cuenta "tanto la larga militancia como la obra periodistica, ambas claramente orientadas en sentido político, no existe la tentación de contrabandear un eslogan o prestarse a la confección de fórmulas propagandistas" (Faeti, 1977: 95). En cambio, intentó proponer una literatura para niños que evitara la manipulación, pero, tal como lo hicieron sus predecesores -y como se hace en la literatura en general-, Rodari expone su pensamiento a través de sus textos. En este caso, plasma sus ideales sociales y su visión de niño de acuerdo con la realidad de la época, es decir, a la situación de la niñez en una Italia que intenta reconstruirse en muchos aspectos luego de la Segunda Gran Guerra.

De esta manera, se da paso a una breve revisión de la vida juvenil del escritor Gianni Rodari donde se dará prioridad a los aspectos biográficos que puedan mostrar las posibles razones de sus elecciones políticas y cómo el autor llega al campo de la literatura infantil. Por último, se presenta su primera obra literaria en prosa I/ romanzo di Cipollino 'La novela de Cebollín' de 1951, nacida a partir de una serie de coincidencias y en un momento histórico de fuertes fervores partidistas, lo que indudablemente influyó en aquel singular estilo que lo ha catalogado como un autor que revolucionó la literatura infantil italiana.

\section{Infancia y adolescencia}

Gianni Rodari nace en la ciudad de Omegna, provincia de Novara y región de Piamonte en octubre de 1920, época en la que Italia trata de paliar las consecuencias sociales y económicas que había dejado la reciente Gran Guerra (1914-1918) y en la que, al mismo tiempo, empieza a tomar fuerza el régimen fascista que gobernará las siguientes décadas.

Giuseppe Rodari, el padre, desarrolla la actividad de panadero y tiene ya un hijo de 12 años cuando se casa con Magdalena Aricocchi, unión de la cual nace el pequeño Gianni. Contando apenas unos meses de vida, "el bebé es confiado a una niñera ya que la madre no puede cuidarlo gran parte del tiempo, pues debe ayudar al marido en el negocio. Aproximadamente un año después nace su hermano César" (Argilli, 1990: 4).

Las restricciones económicas son una constante, pero la actividad familiar, aunque produce recursos limitados, hace la situación llevadera. Sin embargo, Giuseppe muere en 1929 de broncopulmonía. Rodari describe el momento en que vio a su padre con vida por última vez como una imagen que perduraría siempre en su memoria: "un hombre que intenta en vano calentarse la espalda

2 Se ha tomado como referencia la primera edición en italiano del libro, ya que, con el tiempo y por diferentes motivos, el texto se fue modificando y las traducciones conocidas se han hecho a partir del libro cambiado, como es el caso de: Rodari (2013), LaGalera. 
contra el horno. Está empapado y tiembla. Salió bajo un temporal para ayudar a un gatito que se había quedado solo entre los charcos" (Rodari, 1973: 69). Este evento, además del vacío innegable que deja el luto, trajo consigo una serie de cambios en la cotidianidad de la familia, como el traslado de la vivienda a otra ciudad.

Por otra parte, la madre es recordada como una persona rígida y centrada, capaz de controlar sus emociones, muy creyente, que intenta inculcar en sus hijos los preceptos católicos, "una mujer con mentalidad de institutriz, que sabía francés, pues trabajó varios meses en Francia y, por diversos acaecimientos de su juventud, se puede decir que no tuvo una infancia y una adolescencia fáciles" (Argilli, 1990: 6). Es debido a ella que Rodari recibe una fuerte influencia religiosa. De esta manera, a los 11 años, ingresa en el Seminario San Pedro Mártir, ubicado en Milán, del cual se aleja tres años después debido a que llega a considerar humillante la disciplina impartida alli. Desde 1933 hasta 1937 asiste al Instituto Magistral Manzoni, luego, a la temprana edad de 17 años, comienza a dar lecciones particulares que le ayudan a solventar sus gastos personales.

\section{Su vida en tiempos de guerra}

A lo largo del año 1938 trabaja como tutor para una familia hebrea que tuvo que huir de Alemania, hecho que lo acerca de una manera más real al conflicto que se está viviendo en el mundo por aquella época. Desde la fundación en 1937 de la GIL (Gioventù italiana del littorio 'Juventud italiana del littorio'), organización perteneciente al gobierno fascista, adscribirse a ella se convirtió en un requisito obligatorio. De esta manera, "si inicialmente la inscripción a la GIL fue un acto obligado, en los años siguientes fue una necesidad en cuanto se convierte en el instrumento idóneo para encontrar una primera ocupación como empleado" (Macchione, 2013: 72). Por esta razón, Rodari no solo se inscribió a dicho grupo, sino que, en 1941, para poder continuar trabajando, se vio forzado a adherirse al Partido Nacional Fascista. Se transcriben las palabras del escritor, conservadas en cartas inéditas, sobre esta parte de su vida:

Durante el periodo de enseñanza fui forzado a ofrecer mis servicios a la GIL, hacia el sábado fascista para el grupo de menores Balilla (...). No tenía salida, un trabajador habría reaccionado de otra forma, yo era un intelectual pequeño burgués de provincia y tenía los defectos de esta categoría. Cuando, una sola vez, me negué en aceptar un encargo al Fascio de Uboldo (Saronno), me fue infligida para el año escolar de 1943 la calificación de «insuficiente» (Citado en: Argilli, 1990: 12).

Dentro de los factores que influyeron en que Rodari sintiera "el malestar de tener que

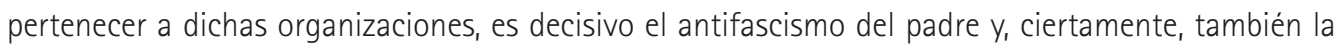
intolerancia a la disciplina humillante que experimentó mientras estuvo en el seminario" (De Luca, 1981: 158).

Debido a quebrantos de salud, Gianni Rodari se libra de prestar el servicio militar en épocas de guerra. Sin embargo, dentro de los fuertes golpes que le dejaron los años bélicos está la muerte de sus dos mejores amigos: Nino Bianchi, quien perece en el naufragio de un barco militar el primer año del conflicto, y Amedeo Marvelli, caído en el frente ruso. Además, su hermano César es internado en un campo de concentración Nazi en Alemania. 
En 1943 vuelve a ser llamado por el ejército de la República Social italiana, allí presta sus servicios en el reparto de sanidad de un hospital de Milán. Un año más tarde, luego de sostener por algún tiempo conversaciones con algunos contactos del Partido Comunista italiano (PCI), deja el uniforme militar fascista y entra en la clandestinidad, se afilia al partido y vive como prófugo hasta el fin de la guerra.

\subsection{Militancia comunista}

A la edad de 16 años, Gianni Rodari tenía como sus filósofos preferidos a Nietzsche, Stirner y Schopenhauer, además, contaba con la madurez intelectual para estar en contra del Imperio proclamado durante la guerra de Abissinia en 1936, ya que lo consideraba, además de injusto, una idea ridícula. Su pensamiento lo llevó, poco a poco, a encontrar y relacionarse con personas afines:

Me volvi amigo de jóvenes trabajadores de Gavirate con los cuales me reunía en las noches. En casa de uno de ellos conocí a uno "que había sido comunista», el compañero Furega Francesco (albañil), de la Sección de Gavirate, comunista en 1921, que me contó a su manera el nacimiento del Fascismo. (Argilli, 1990: 10)

También se dedicó a leer la vida de Lenin, de Stalin, la autobiografía de Trotzki y su Historia de la revolución (1930); libros que le dieron las herramientas justas para hacer una crítica consciente sobre la situación política que vivian y que despertaron su curiosidad sobre el Marxismo como concepción del mundo. En los años de guerra, afiliado a la GIL y adscrito al Partido Fascista, conoció la miseria, el desempleo y la vergüenza de ser parte de un movimiento que detestaba, pero que representaba la única forma de ubicación laboral.

Haber pertenecido al Partido Fascista, aunque fuese una acción necesaria en un determinado periodo, lo atormentó durante mucho tiempo. Sobre el sentimiento que probó al ser convocado por el Movimiento de Resistencia, Rodari escribió: "Me avergonzaba mucho de mis "precedentes» por el hecho de que la invitación venía dirigida por un compañero que había estado algunos años en el confinamiento y de otro que había sido batido varias veces por los fascistas" (Citado en: Argilli, 1990: 12). Cuando fue contactado por los integrantes del PCl para sumarse a ellos, sus convicciones lo ayudaron a prestar sus servicios a la Resistencia y, al mismo tiempo, seguir afiliado al fascismo. No obstante, esto no tardó en revelarse insostenible. Por esta razón, decidió vivir en el anonimato.

Tras el final de la Segunda Guerra Mundial, Rodari dedicaría su vida a la escritura. Tanto en su faceta de periodista como en la de autor para niños, se destaca su empeño por llevar al público un mensaje que cultivara valores, pensamientos $y$, tal vez, reacciones que fueran en contraposición al ideal fascista; labor inconmensurable en un periodo de letargo y marcadas oposiciones políticas. Como expresa Roghi (2020: 8), "que la palabra fuera el único instrumento para imaginar tiempos nuevos era una creencia de muchos, $y$, aunque el mundo fuera opaco, incierto y la imaginación pareciera una vía de escape privatizada, hubo quienes decidieron cultivarla".

\section{Profesión en la postguerra}

Después de la Liberación italiana, Rodari decide dedicarse a la política, por lo que se convierte en funcionario del $\mathrm{PCl}$ a tiempo completo. Su compromiso con el partido es intenso, en el primer año de servicio funda el periódico mimeografiado Cinque punte, distribuido en la región de Lombardía, 
es nombrado inspector de zona para la organización de la Federación de Varese, responsable de la Comisión Juvenil de Federación, luego gestor de la Comisión de Prensa y Propaganda y director del semanario I'Ordine Nuovo; además de ser miembro de la Secretaría de la mencionada federación.

En estas primeras tentativas profesionales descubre la que será una de sus grandes pasiones, el periodismo, labor que ya jamás abandonará. No obstante, al mismo tiempo se ejercita como escritor literario, entonces publica la transcripción de algunas historias populares, además de escribir poesias y cuentos y, por entregas, cotraducir La línea Política (1930), drama didáctico con temática marxista, de Bertolt Brecht (1898-1956). En 1947 deja su función como director de I'Ordine Nuovo para convertirse primero en cronista y luego en subdirector y enviado especial para I'Unità de Milán.

En este punto, sus intenciones futuras eran claras, desarrollaria su profesión y se especializaria como periodista para el $\mathrm{PCl}$, pues esta actividad lo apasionaba y sentía tener una gran oportunidad al trabajar para un periódico de circulación nacional, además, vivía en una gran ciudad y, a sus 27 años, intuía que este oficio le brindaría la estabilidad propicia que buscaba.

Rodari se destaca como periodista dentro del círculo de la prensa comunista. Para él, la tarea del corresponsal serio y democrático debía ser "ir y ver lo que pasa a la gente, a la no paradigmática que toma el autobús, que va a la oficina, que vive una vida cotidiana. Contar aquello que les sucede y luego reflexionar sobre ello" (Bini, 1982: 156). Esto denota la importancia que, desde sus inicios, Rodari otorga a la situación y a las necesidades de las clases populares.

A pesar de lo cómodo que se sentía en aquella situación laboral y personal, en ese momento comienza a suceder aquello que guiará el devenir de Rodari en las siguientes décadas. Mientras trabaja para I'Unità, comienza a escribir ocasionalmente para niños. Si bien este sería un evento independiente de su voluntad, "marcará un punto de inflexión fundamental en su vida, incluso si aún deben pasar varios años antes de renunciar definitivamente al periodismo militante o a una perspectiva política para dedicarse tanto a la literatura infantil como al periodismo no partidista" (Argilli, 1990: 16).

La dirección del periódico decide que habrá una pequeña sección semanal dedicada a los niños, coordinada por Rodari, esta se llamará La domenica dei piccoli 'El domingo de los pequeños'. Alli el escritor publicó sus primeras poesias infantiles que, si bien las había escrito solo por compromiso con el periódico, tuvieron muchísimo éxito entre los lectores. "Sus poemas son sugestivos porque consignan el testimonio de un Rodari particularmente atento a la realidad social de principios de los años 50: aparecen sobre todo caracterizados de una intención más directamente política" (Boero, 1981: 184).

Este encargo se prolongaria por casi dos años; sin embargo, sus intereses seguian siendo periodísticos y políticos, incluso literarios, pero en un sentido amplio. Sentía que su responsabilidad cultural y social todavía era desarrollarse dentro del Partido Comunista, ya fuese como periodista o haciéndose un lugar en el ámbito político.

\section{Años como director de il Pioniere (1950-1953)}

Para ampliar sus alcances en la población juvenil y afianzar la estructura de la API (Asociación Pioneros de Italia), organismo del PCl que agrupaba a niños entre 8 y 13 años, el partido se dio a la tarea de publicar un semanario destinado exclusivamente a los pequeños. Para la dirección de este serían designados Dina Rinaldi, ya directora de la publicación Noi Donne, y Gianni Rodari, único 
periodista que habia demostrado con éxito sus habilidades en la escritura para niños. Aunque dichos cometidos no representaban obligaciones que debian acatarse sin refutar, en aquella época el escritor se caracterizaba por su disponibilidad y empeño con el Partido, por esta razón debió transferirse a Roma, no muy entusiasta, para cumplir con el encargo. El semanario se llamaría il Pioniere y su codirección llevaria de forma automática a Rodari también a presidir la API.

Dirigir el semanario representó la oportunidad para que Rodari comenzara a ocuparse profesionalmente de literatura infantil. Sin embargo, todavía no consideraba la idea de convertirse en un escritor para niños, lo confirma el hecho de que sus primeros libros "nacen solo porque le han sido solicitados" (Argilli, 1990: 17). A pesar de esto, la propuesta de Rodari aparece en un momento crucial en el que la literatura infantil se estaba tornando en una herramienta de evasión de la realidad que incentivaba la desconexión de los niños hacia los problemas reales de la gente. Contra esta indiferencia es que "interviene el escritor, no solo evidenciando críticamente los mecanismos de los que se vale el procedimiento hacia aquel desinterés, sino concretamente operando porque sus "fábulas» puedan creativamente testimoniar también un puntual compromiso ideológico y político" (Faeti, 1977: 95).

Es por esta razón que Rodari "no se dirigía al «vulgo»: ni al vulgo de niños a quienes debía encantar, ni al vulgo de lectores a quienes debia entretener tratando juguetona y superficialmente temas muy serios" (Lombardo Radice, 1982: 7). Su objetivo era el ciudadano sin distinciones, el pequeño coterráneo que desarrollaría la razón suficiente para entender los ideales de paz y de libertad que él profesaba.

Entonces, estos primeros escritos para niños surgen con una evidente carga del pensamiento del autor acerca de la sociedad de la época. Debido a esto, si se quiere comprender de forma justa a Rodari, se necesita tener en cuenta tanto "sus experiencias infantiles y adolescentes, como aquellas de la guerra, de la Resistencia y de la participación en el impetuoso movimiento democrático y popular de la inmediata posguerra vivido como funcionario de Partido, periodista, director de semanarios y dirigente político" (Argilli, 1981: 27). Así, se entiende que el escritor, aunque llega a la literatura infantil de forma casual, logra una ruptura que lo resalta dentro del canon. Esto, debido a que "trasgrede algunas convenciones básicas de su tiempo, como que la literatura para niños es una lección enseñada de arriba hacia abajo. En contraposición, demuestra que el adulto y el niño tienen una complicidad en el campo de la fantasía" (Roghi, 2020: 7).

\subsection{El Manual del Pionero}

Como director de la API, Gianni Rodari crea el Manual del Pionero (1951), libro donde se consigna el código de comportamiento y las actividades que deben desarrollar los grupos juveniles adscritos a la asociación. El escritor ve en esta la ocasión de organizar en dicho volumen todo un empeño pedagógico por formar a la juventud en concordancia con los ideales en los que él mismo cree; idea que expresa en la parte primera de su manual:

En el nuevo clima nacional y social que surge de la lucha contra el fascismo y de la victoriosa guerra de liberación, el pueblo italiano ha logrado su educación democrática. La vida de grandes masas de trabajadores y de provincias enteras ha sido completamente transformada. Una nueva concepción de la vida ha inspirado a millones de hombres y de mujeres un nuevo modo de comportarse, desarrollando en ellos el espíritu de iniciativa, la capacidad de una intervención directa y activa de cara a renovar la sociedad italiana, la vigilancia y la lucha por la defensa de los derechos laborales, de la libertad y de la paz. (Rodari, 1951a: 5) 
Para su fundación, la API reunió a los jóvenes que en distintos lugares de Italia se habian ido juntando de forma espontánea en torno a la conservación de los ideales de libertad y paz proclamados al final de la Segunda Guerra Mundial. En el manual se exponen los principios de la asociación, las características que debe tener un dirigente y cómo serán distribuidas y realizadas las actividades que el mismo propone.

El libro es, ante todo, una herramienta que intenta generar algunas normas y patrones comportamentales dentro del colectivo para fomentar un sentimiento de unidad con el cual sus integrantes se identifiquen. Se deja claro lo que se espera de cada uno de ellos, ya sean dirigentes adultos, líderes jóvenes o asociados niños. Aunque es evidente el empeño en marcar una diferencia con otras agrupaciones juveniles, al mismo tiempo se promueven unos estándares de respeto por los demás y sentimientos estimulantes frente al trabajo comunitario y el amor a la patria.

\subsection{Semanario il Pioniere}

Su desempeño como director de il Pioniere fue tan importante para la cultura juvenil italiana como decisiva en su vida profesional. La maduración y el camino que siguió el semanario se debieron, en su mayor parte, al trabajo que desarrolló Rodari, pues era él quien definía los temas, los personajes, el lenguaje y velaba por la relación que se desarrollaba entre el periódico y la API. De esta manera, "dio vida al primer semanario italiano que hablaba a los jóvenes de ideales de paz y de solidaridad entre muchachos de todas las ciudades y condiciones sociales, como también de igualdad entre las razas" (Argilli, 1990: 65). Por primera vez en una publicación infantil, se eliminaron los estereotipos racistas que en la época dominaban la literatura; por ejemplo, el Piel roja ya no era feroz y salvaje (Imagen I: 'Sitar, la verdadera historia de los Piel roja'), se le otorgaron las características humanas que los cómics estadounidenses habían casi eliminado; además, los héroes ahora provenían del mundo de los esclavos, de los guetos negros, de las clases desfavorecidas, de los trabajadores, de los partisanos.

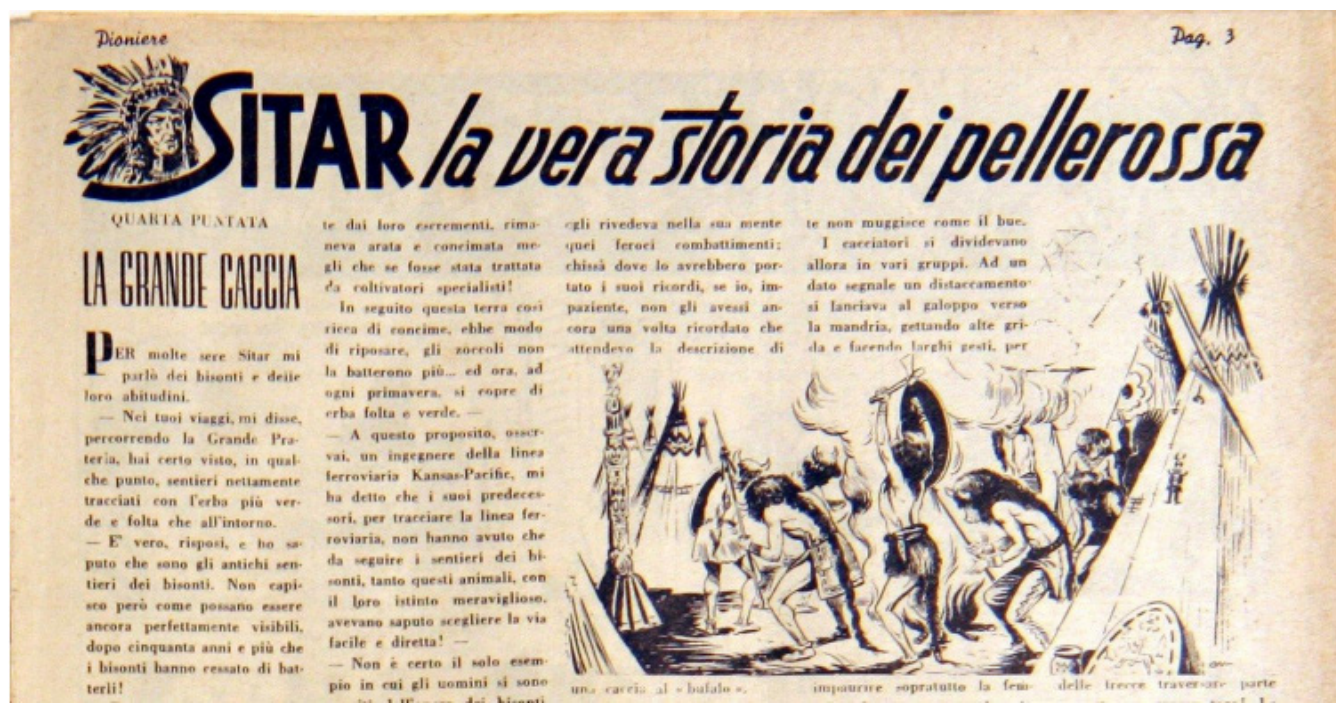

Imagen 1. // Pioniere. No. 4, septiembre 24 de 1950, p. 3.

Sin embargo, el periódico no estuvo exento de polémicas. A pesar de que en la publicación jamás aparece una mención atea y que ni siquiera existiese un comentario irreverente en contra de 
la Iglesia, il Pioniere fue siempre tácitamente seglar. Por esta razón, fue juzgado por diversos grupos religiosos como un medio para la corrupción de los niños debido, sobre todo, a que el periódico era publicado por un grupo comunista. Entonces, los párrocos lo prohibian en sus templos y hubo incluso episodios de quemas de ejemplares como símbolo de satanización de los mensajes expresados en el semanario.

Dicha cruzada clerical en contra de il Pioniere fue muy agresiva. "Los «Pioneros» llegan a ser excomulgados por decreto del Santo Oficio; también fueron blanco de una sistemática campaña calumniosa y denigratoria que desembocó en algunos procesos legales" (Negrello, 2000: 100), como, por ejemplo, el folleto de Lorenzo Bedeschi: Dissacrano l'infanzia i Pionieri d'Italia (1950) 'Profanan la infancia los Pioneros de Italia', y el de Tommaso Toschi: La maschera e il volto, verità su l'opera antireligiosa del PCl (1952) 'La máscara y el rostro. La verdad sobre la obra antirreligiosa del PCl'.

Es claro que il Pioniere había nacido a partir de un esfuerzo ideológico. Se debe recordar que Rodari era "un intelectual de fuerte vocación marxista: aspecto que se debe tener presente constantemente para una comprensión no superficial del autor, quien encontró un espacio para su impetuoso aliento social, sobre todo, en la producción para niños" (Genovesi, 1982: 126). Sin embargo, il Pioniere no se ocupaba de política. El empeño, tanto de la publicación como de la API, se sostenía en el hecho de reforzar y mantener los ideales sociales expresados por medio del juego y la fantasía. Argilli (1990: 66) sostiene que, precisamente, "es esta la gran contribución que Rodari dio al periodismo italiano para la infancia, con invenciones del todo italianas, sin mínimamente referirse a los modelos pedagógicos y propagandistas soviéticos para niños". Los escándalos que se presentaban en torno a la aparición de un semanario hecho por un grupo comunista y dirigido a los niños, en realidad, responden al miedo habitual de una sociedad tradicionalista frente al cambio.

\section{Cebollín, el héroe de la revolución}

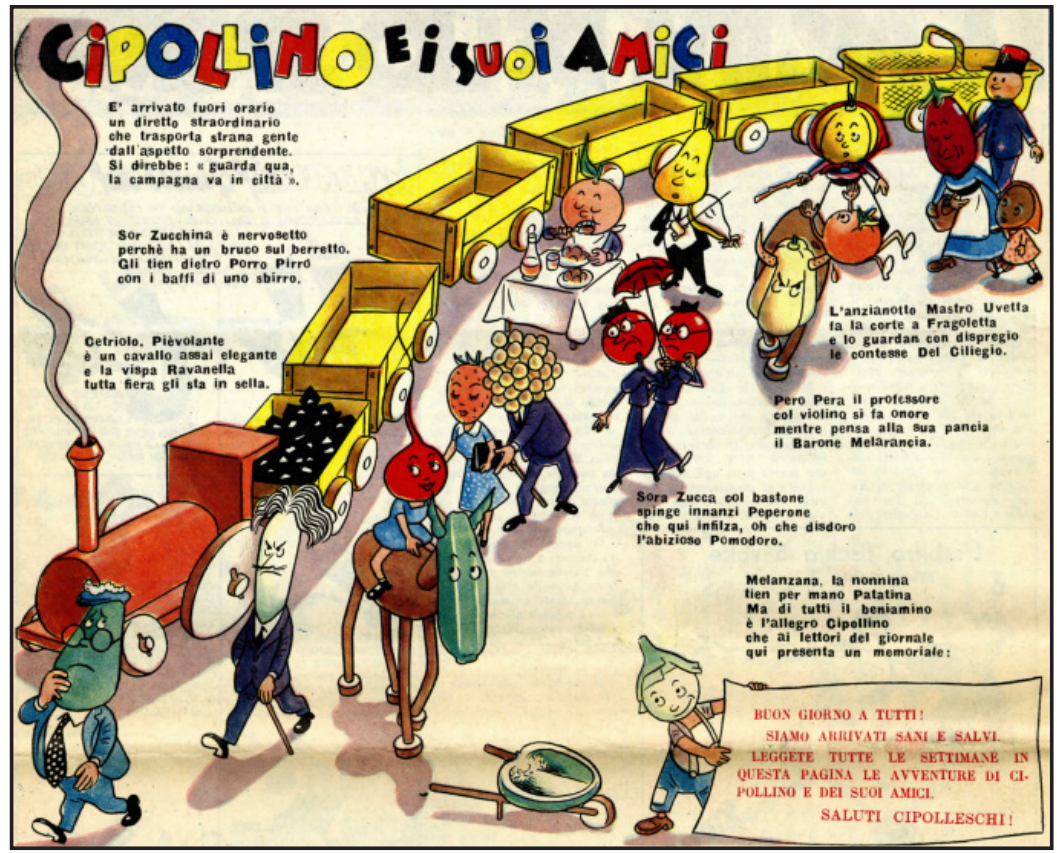

Imagen 2. I/ Pioniere. No. 1, septiembre 3 de 1950, p. 6 
Cebollín es el personaje insigne de los primeros años de il Pioniere. Aparece desde el primer número del semanario con una introducción de los personajes y de lo que sería una serie de aventuras. La parte final del texto en la Imagen II dice lo siguiente: "Berenjena, la abuelita / tiene de la mano a Patatita. / Pero de todos el más querido / es el alegre Cebollin / que a los lectores del periódico / les presenta un memorial: / Buenos días a todos: hemos llegado sanos y salvos. Lean todas las semanas en esta página las aventuras de Cebollin y de sus amigos. iSaludos cebollescos!" (Rodari, 3 de septiembre 1950).

Gianni Rodari decide contar las aventuras de un mundo vegetal en versos octosilabos (sin ser estricto siempre en la medida), e ilustrados por Raul Verdidni. "Con el paso del tiempo, Cebollin se convertirá en el personaje símbolo de il Pioniere, aparecerá en separadores de libros, postales, y su nombre será un referente para los niños de la API" (Greco, 2014: 40).

\subsection{La novela de Cebollín}

El éxito del personaje de Cebollin se confirma y se reafirma en 1951 cuando se decide publicar una historia más larga en un libro que llevará como título La novela de Cebollín. Dicho volumen tuvo gran acogida dentro del público infantil, sobre todo, de paises extranjeros y, más que nada, de Europa del Este. Por esta razón, fue traducido a diferentes lenguas como el ruso, el francés, el alemán, el chino, el japonés, el polaco, el búlgaro, el rumano, el húngaro, entre otros. Es especial el caso de la URSS, pues este libro (junto a la recopilación de sus primeros poemas) es recibido con ferviente entusiasmo. Los niños soviéticos encuentran todo lo que todavía no han visto en sus autores, "la voz anticonformista de un poeta que expresa ideales avanzadisimos con absoluta libertad, sin pretensiones pedagógicas ni panfletarias, sin los moralismos que todavía caracterizan la producción del país soviético, aún con temas y poéticas propias de una anacrónica sociedad campesina" (Argilli, 1970).

Como la casa editorial Edizioni di Cultura Sociale, que distribuía los libros de Rodari en Italia, pertenecía al $\mathrm{PCl}$, contaba con una circulación limitada. Por esta razón, el periodista comenzó a ser reconocido como escritor para niños en otros lugares antes que en su propio país. Con las posteriores reediciones y, sobre todo, cuando en 1960 empieza a hacer parte del catálogo de la editorial italiana Einaudi, la más importante de la época, su obra y su nombre adquieren en Italia la fama que ya tenía en otros paises.

Esta fascinación que producen sus obras, efectivamente, se debe a que "Rodari contribuye a introducir nuevos temas en la literatura para la infancia: las diferencias sociales, la explotación laboral, el antimilitarismo, la solidaridad entre los oprimidos" (Boero \&t De Luca, 1995: 257). El escritor se afirma como una novedad literaria. Su llegada al ámbito infantil se habia dado gracias a una serie de coincidencias que le permitieron mantener sus ideales sociales sin renunciar a expresar "un proyecto político propio, sólidamente correlacionado a una dimensión histórica cuyos términos se afrontan con cotidiana y sufrida paciencia. En Rodari los contenidos de una reconocible ideología encuentran vehículos adecuados sin disfrazarse o sin complacer o aclamar absurdamente su superficie" (Faeti, 1977: 95). Todo esto por medio de un lenguaje cercano a la realidad del niño y una escritura clara, entendible y divertida. Por ejemplo, el uso del lenguaje de forma irónica da al libro diversos rasgos de sátira política en frases como la siguiente: "El Gobernador Príncipe Limón cree ser un gran líder, y no encuentra paz si no puede hacer alguna guerra, incluso falsa" (Rodari, 1951: 79).

Por otra parte, lograr un tono y un lenguaje apropiados para los niños de toda Italia no fue un trabajo fácil. Es necesario recordar que "entre el final de los años cuarenta y el inicio de los años cincuenta, cuando Rodari aparece como escritor y poeta para la infancia, la lengua italiana aún no 
era un patrimonio suficientemente difundido en toda la península" (Boero \&t De Luca, 1995: 259). Casi a un siglo de la Unificación de Italia, por razones que van desde las bajas tasas de alfabetización hasta las dificultades que conlleva el desprenderse de la base de la propia cultura, la península aún no contaba con un idioma estandarizado. Era claro que el concepto de un país unificado por la lengua aún no era una realidad en Italia, lo que contradecía los postulados de siglos anteriores donde se relacionaba la frase " "hablar la misma lengua» con "ser de la misma nación» como si se tuviera que sobreentender su fundamental aplicabilidad al territorio y al pueblo de un pais como Italia" (Trifone, 2017: 24).

Frente a esta dificultad, Rodari encuentra los instrumentos lingüisticos adecuados para todos sus interlocutores, más que en su "natural disposición a la inventiva literaria, en la experiencia periodística que le hizo madurar una extraordinaria capacidad de permanecer en los hechos y elaborar un lenguaje claro y preciso, capaz, al mismo tiempo, de llegar al núcleo de los problemas" (Boero \& De Luca, 1995: 260).

Por otra parte, aún después de la censura fascista, "los libros para niños conservaban un tono marcado de mensajes constructivos, tradicionales de la herencia De Amicis, y a los contenidos los invadia una serie de preceptos morales que ratificaban el conformismo literario aún latente en la cultura" (Argilli, 1970). Contra esto se revela Rodari, quien evita ser condescendiente con la niñez y se empeña en dirigirse a los niños, no necesariamente como si fuesen adultos, sino como seres que pueden entender su realidad a través de la fantasía.

En consecuencia, gracias a la popularidad del personaje, Rodari crea su primera novela. "Para escribirla, pide una licencia no remunerada. Entonces, al no tener el suficiente dinero, el mismo partido le encuentra una familia de compañeros partisanos que lo hospeda" (Argilli, 1981: 39). El propio autor recordaba la anécdota:

Tomé un mes de vacaciones, encontré hospedaje en la casa de un buen campesino de Gaggio di Piano, en Módena, quien desocupó una habitación-bodega para acomodarme una cama, la sección del PCl me prestó su máquina de escribir y comencé Las aventuras de Cebollín. Fue un mes bellísimo. Las hijas de Armando Malagodi -el campesino que me hospedaba- me llamaban temprano en la mañana: ¡Arriba, Gianni! Que estás aquí para trabajar, no para dormir. (Rodari, 4 de marzo 1965)

La novela de Cebollin narra la travesia de un «niño» que busca la manera de liberar a su padre, quien, a causa de las recurrentes injusticias que suceden en su pueblo, es preso por el Príncipe Limón, un monarca sin escrúpulos que disfruta el buen vivir y ama satisfacer sus propios caprichos sin importar a quién pueda afectar. En su camino, encontrará diferentes personajes que reafirmarán el deseo de Cebollín de ver una nueva sociedad justa y sin distinciones, y muchos se unirán a él logrando derrotar al Príncipe Limón y a su abusiva familia para dar paso a la República.

Se puede decir que /l romanzo di Cipollino "participa en la experiencia del neorrealismo en "clave cortésmente irónica y surreal»" (Argilli et al., 1993: 12), pues, aunque la obra utilice la fantasía para recrear sus escenarios, es concreta en su critica hacia la sociedad. Los personajes principales de la obra son las hortalizas antropomorfizadas, ya protagonistas del cómic, que se mueven en una realidad campesina y artesanal en el interior de una sociedad de la que el autor pone en evidencia las relaciones sociales desequilibradas. Según Rossitto (2011: 30) uno de los rasgos neorrealistas es rastreable en la simpatía con que Rodari "deposita en el pueblo valores positivos 
como la solidaridad, contraponiéndolo a la Monarquía que, en cambio, representa el residuo de una prepotente civilización feudal que continúa prosperando a expensas de las clases subalternas gracias a sus propios privilegios".

Rodari compartía con los existencialistas la idea de la literatura como herramienta, mismo pensamiento que defienden escritores como Mario Vargas Llosa, quien habla del ejercicio de escribir no solo como instrumento de creación de objetos estéticos, sino también de transformación histórica, la noción de que con un poema o una novela se puede influir en la Historia y provocar cambios positivos en una sociedad. Esto quiere decir que "la vocación del escritor no es gratuita, que, asumiendo la aptitud de artistas, de creadores, de escritores, se puede contribuir a sacar una sociedad del pozo en el que se encuentra, un pozo de injusticia y de falta de libertad" (Vargas Llosa, 2003: 29).

Desde esta perspectiva, La novela de Cebollín es el intento rodariano de exponer los peligros sociales de un sistema económico y político injusto, que divide al pueblo en clases, según sus pertenencias o títulos nobiliarios, y donde el pobre es sometido a la ignorancia y a la escasez, con impuestos impagables e inicuos, todo para perpetuar la brecha económica que mantiene a los acaudalados en el poder, como se observa en el siguiente pasaje:

La gente estaba bastante asustada porque cada vez que se reunía el Tribunal había problemas. La última vez, por ejemplo, el Tribunal decidió que el aire era propiedad de las Condesas del Cerezo y que entonces se debía pagar un alquiler a la administración del Castillo por aquel que se respiraba. Una vez al mes, Tomate visitaba las casas, hacia respirar profundamente en su presencia a los ciudadanos y tomaba la medida de sus respiros, después hacía algunas multiplicaciones y concluía fijando una cifra que se debia pagar por respirar. (Rodari, 1951: 219)

En una ciudad donde las frutas y las verduras son "una metáfora de la sociedad civil y de los mecanismos que la regulan" (Greco, 2014: 40), Cebollín representa al héroe del pueblo, al vocero de los oprimidos. Su astucia lo lleva a emprender una cruzada en contra de los prepotentes gobernadores. El detonante de sus acciones es, como era de esperarse, una experiencia personal: su padre es llevado a la cárcel por una razón injusta; pero sus motivaciones van más allá, Cebollín descubre que su padre no es el único prisionero por "equivocación», entiende que el problema es el abuso de poder en una sociedad que no reacciona:

-iPobre papá! te han puesto en prisión como a un malhechor, junto a los peores bandidos.

-Hijo mío, quítate esta idea de la cabeza, - le dice el padre afectuosamente -en prisión hay todo un ramillete de caballeros respetables.

- ¿Y qué hicieron mal?

-Nada. Precisamente por eso están en prisión. Al Príncipe Limón no le gusta la gente buena. (Rodari, 1951: 8)

Rodari da a Cebollín las caracteristicas de un líder pacífico, del hombre que busca la paz sin recurrir a la guerra. Sin embargo, no olvida los «disparos» revolucionarios, la fuerte polémica contra la injusticia, la idea de que "una lucha social no puede ser combatida solo con las armas de la ironía y de la profanación paródica y en algunos casos hace que su indignación sea explícita, la voluntad de resarcimiento a través de afirmaciones fuertes" (Boero, 2010: 94). Tras el libro hay una determinación expresa, exponer los abusos de los regímenes autoritarios que solo pueden ser combatidos a partir 
de la acción colectiva. Entonces, derrocado el régimen monárquico despótico, los abusadores son vencidos y exiliados:

-Aqui se está al calor y con tranquilidad- decia el Gobernador, escupiendo el estiércol que le había entrado en la boca. -Me quedaré en este lugar hasta que mis guardias hayan restaurado el orden público.

Al haber escapado sin mirar atrás, no sabia ni siquiera que sus guardias se habian liberado, que sus soldados Limones Ilenaban las cárceles y que había sido proclamada la República. (Rodari, 1951: 227)

Es de resaltar que, en el universo vegetal de Cebollín, perteneciente aún a una Italia campesina, el tema de la instrucción sea presentado como "posibilidad de redención de la miseria, como vehículo principal de la conciencia de clase y de la voluntad de reivindicación" (Boero, 2010: 91). De esta manera, cumplidos los objetivos, no restaba más que contribuir a la construcción del mundo ideal, un lugar equitativo, con oportunidades, donde los niños sean tratados como tales y respetados, donde haya espacios para su diversión, su esparcimiento y su educación:

El Castillo ya no es un Castillo, sino una casa de juegos. Para niños, se entiende: está la sala de ping-pong, la sala de dibujo, la sala de marionetas, la de cine, etcétera, etcétera. Naturalmente existe el juego más bello, o sea, la escuela: Cebollin y Cerecito se sientan juntos en el mismo pupitre y estudian aritmética, lengua, historia y todas las otras materias que es necesario conocer bien para defenderse de los bribones y mantenerlos lejos. (Rodari, 1951: 239)

Por último, una de las grandes rupturas que ofrece La novela de Cebollin, con respecto a los cuentos de hadas tradicionales, es la victoria final. En las narraciones clásicas, la conclusión es simbolizada por goces personales, es decir, el protagonista de las fábulas populares adquiere logros como la reivindicación de su honor, la mano de la hija del rey, una fuente permanente de riqueza. Sin embargo, en la obra de Rodari, "la conclusión de la historia establece el logro de una mejora colectiva a través del triunfo de los ideales revolucionarios" (Rossitto, 2011: 31). Es decir, aunque Cebollín es el héroe de la revolución, es el pueblo el que consigue la victoria y, por ende, goza de la recompensa, representada ya no en grandes riquezas materiales, sino en la consecución de condiciones justas de convivencia.

\section{Conclusiones}

La literatura infantil ha sido usada, en muchos casos y con diversa intensidad, como un medio tanto para el aprendizaje y el esparcimiento como para la transmisión de contenidos ideológicos. La historia ha demostrado cómo el adulto, de forma directa como fortuita, se ha empeñado en proponer modelos comportamentales infantiles que guien su cotidianidad para que desde pequeños aprendan los preceptos morales de una sociedad particular.

Es indiscutible el hecho de que cada autor revela, por medio de su literatura, una posición crítica frente a la sociedad en la que ha vivido. A través de la voz narradora se consigue imprimir una visión de mundo ya sea de manera explícita o sugerida, consciente o inconsciente. Como expone Colomer (2002: 73), "cuanto más lejanos en el tiempo y cuanto más explícita y deliberada ha sido la 
valoración moral introducida, más detonantes resultan los valores y modos de pensar reflejados en las obras". En el caso de // romanzo di Cipollino, esta ideología está bastante acentuada, resulta sencillo deducir que el héroe de la historia está en contra del establecimiento, lo que lo describe políticamente como un individuo de izquierda y cuyo pensamiento en gran medida -aunque aqui de forma menos subrayada y guiados solo por la filiación politica del escritor- pertenece a los ideales comunistas.

De acuerdo con esto, se puede afirmar que Rodari ha creado su obra a partir de experiencias personales, pues, vivir su juventud durante el periodo fascista, la experiencia que tuvo al acercarse a la religión, conocer el Fascismo en primera persona y las grandes tristezas que le trajo el conflicto bélico, entre otros eventos, forjaron sus ideales y lo llevaron a escribir de forma consciente sobre la realidad social de Italia en aquel momento histórico.

El periodismo le habria brindado el conocimiento cultural e investigativo suficiente para forjar sus facultades intelectuales y ofrecer a la cultura italiana una nueva forma de concebir la prensa infantil. Entonces, il Pioniere representa uno de los momentos más importantes de su vida profesional. Dicho semanario sería el laboratorio donde experimentó sus contenidos, donde afianzó su modo de escribir y decidió el rumbo que tomaría su literatura.

Queda claro que Rodari no fue un hombre propagandista. Tanto sus escritos como las publicaciones que él coordinó no pretendieron emitir mensajes políticos; su intención siempre fue la de exponer el ideal de sociedad justa y equitativa que su experiencia personal lo llevó a plantear. Por tanto, los ataques que sufren el semanario y la API responden al miedo de la sociedad al cambio $y$, sobre todo, al temor de grupos particulares que vieron en dichos empeños una amenaza a sus propios afanes. Por ejemplo, con respecto a los ataques clericales, es válido resaltar que en aquella época la Iglesia católica tenía, como una labor de su entera exclusividad, la enseñanza de los niños, en consecuencia, optó por defenderse, si bien a través de medios polémicos, de las nuevas propuestas que iban en contra de sus intereses. Sin embargo, contrario a la intención de estos ataques, la polémica otorgó valor a las acciones de Rodari, llamó tanto la atención que logró exaltar la disposición del semanario por crear alternativas que promovieran nuevas formas de pensar, precisamente en un periodo en el que era necesario un cambio de perspectiva en el ámbito político y social.

Por otra parte, es acertada la decisión de Rodari de expresarse por medio del uso popular del lenguaje para que el lector lograra sentirse parte de la narración. Teniendo en cuenta lo anterior, La novela de Cebollín se convirtió en la oportunidad para expresar su pensamiento a través de la creación de un universo fantasioso. Entonces, con Cebollin, el escritor propuso al paladín social con características de un buen líder: pacífico, amistoso, fiel y valiente, para que llevara la batuta de una revolución necesaria en una aldea cansada de los abusos y de las injusticias.

La obra de Rodari expone sus ideales al mismo tiempo en que logra alejarse de la manipulación, es decir, no decreta, al contrario, muestra, revela, cuenta sus afanes sin el ánimo de generar en los niños algo más que la reflexión. Rodari irrumpe con un pensamiento personal sobre el momento histórico en el que vive y ofrece una literatura y un periodismo infantiles revolucionarios porque se despega de los estereotipos que determinan patrones de comportamiento hacia lo que no se conoce.

Mantenerse al margen de lo establecido y de todo dogma religioso es un acierto irrebatible, pues aquella decisión logró enriquecer sus planteamientos al darles un sentido más humano, más universal y, sobre todo, más cercano a la realidad. Así, se desprendió de prejuicios tradicionalistas que, sin duda, hubiesen eclipsado el verdadero mensaje de paz, de unión y de igualdad.

Para finalizar, se debe hacer énfasis en que la gran admiración que adquirió Rodari con el tiempo, no solo en el medio artístico sino en la colectividad general italiana, en gran parte se debe 
al hecho de evitar tratar a los niños como seres incapaces de entender su entorno social. Por esta razón, los alcances de su literatura son casi ilimitados, pues su obra ha sido apreciada tanto por los niños como por los adultos, ya que, en ella, como observa Faeti (1977: 96), "hay una tranquila, pero inflexible, defensa de una dimensión divergente a la que no se le dan complejas motivaciones estéticas, sobre todo porque aquella no exige ser considerada rara o única, sino porque pretende, creiblemente, pertenecer a todos".

\section{REFERENCIAS BIBLIOGRÁFICAS}

ARGILLI, M. (1970). Favole ed ideologia: Gianni Rodari. En: Didattica di Riforma, supplemento al n. 2, Roma.

ARGILLI, M. (1981). Quando Rodari era il diavolo. En: Bini G (a cura di). Leggere Rodari. Supplemento a "Educazione Oggi» (pp. 23-50). Pavia: Amministrazione provinciale - Ufficio Scuola.

ARGILLI, M. (1990). Gianni Rodari. Una biografia. Torino: Einaudi.

ARGILLI, M., DEL CORNÒ, L. \& DE LUCA, C. (a cura di) (1993). Le provocazioni della fantasia: Gianni Rodari scrittore ed educatore. Roma: Editori Riuniti.

BINI, G. (1982). Fantasia e ragione. En: Ghilardi F (a cura di). II favoloso Gianni: Rodari nella scuola e nella cultura italiana (pp. 154174). Firenze: Nuova Guaraldi.

BOERO P. \& DE LUCA C. (1995). La letteratura per l'infanzia. Roma: Laterza. 2009.

BOERO, P. (1981). Biografia ragionata. En: Bini G (a cura di). Leggere Rodari. Supplemento $a$ «Educazione Oggi» (pp. 83-104). Pavia: Amministrazione provinciale - Ufficio Scuola.

BOERO, P. (2010). Una storia, tante storie. Guida all'opera di Gianni Rodari. Trieste: Einaudi.

CAMBI, F, (1985). Collodi, De Amicis, Rodari: Tre immagini d'infanzia. Bari: Edizioni Dedalo.

COLOMER, T. (2002). Siete llaves para valorar las historias infantiles. Madrid: Fundación Germán Sánchez Ruipérez. 2005.

DE LUCA, C. (1981). Un giornalista con il gusto di raccontare. En: Bini G (a cura di). Leggere Rodari. Supplemento a "Educazione Oggi» (pp. 156-202). Pavia: Amministrazione provinciale - Ufficio Scuola.

FAETI, A. (1977). Letteratura per I'infanzia. Firenze: La nuova Italia. (1985)

GENOVESI, G. (1982). Un mondo di fiaba. En: Ghilardi F (a cura di). Il favoloso Gianni: Rodari nella scuola e nella cultura italiana (pp. 125-138). Firenze: Nuova Guaraldi.

GRECO, R. (2014). "Educare senza annoiare, appassionare senza corromperen: Gianni Rodari e la direzione del Pioniere (19501953). Como: Il Ciliegio.

LOMBARDO RADICE, L. (1982). Introduzione. En: Ghilardi F (a cura di). II favoloso Gianni: Rodarinella scuola e nella cultura italiana. (pp. 1-11). Firenze: Nuova Guaraldi.

MACCHIONE, P. (Coord.). (2013). Storia del giovane Rodari. Varese: Pietro Macchione.

NEgRellO, D. (2000). A pugno chiuso. // Partito comunista padovano dal biennio rosso alla stagione dei movimenti. Milano: FrancoAngeli.

RODARI, G. (3 de septiembre 1950). Cipollino e i suoi amici. /l Pioniere. n. 1, p. 6.

RODARI, G. (1951). I/ romanzo di Cipollino. Roma: Edizioni di Cultura Sociale.

RODARI, G. (1951b). Manuale del Pioniere. Roma: Edizioni di Cultura Sociale.

RODARI, G. (4 de marzo 1965). Gianni Rodari racconta come diventò scrittore: Storia delle mie storie. I/ Pioniere. Supplemento del giovedi dell'Unità. n. 9, p. 4. 
RODARI, G. (1973). Grammatica della fantasia. TOVAR MÉNDEZ, R.A. (2017). "Desde Pinocho, Introduzione all'arte di inventare storie. Roma: Einaudi.

RODARI, G. (2013). Las aventuras de Cebolleta. Trad. Esp.: Angelina Gatell. Barcelona: LaGalera.

ROGHI, V. (2020). Lezioni di fantastica. Storia di Gianni Rodari. Bari: Laterza.

el niño rebelde, hasta Cebollin, el niño revolucionario". Anuario de Investigación en Literatura Infantil y Juvenil 15, pp. 171-186.

TRIFONE, P. (2017). Pocoinchiostro: Storia dellitaliano comune. Bologna: II Mulino Società Editrice.

ROSSITTO, M. (2011). Non solo filastrocche. Rodari e la letteratura del Novecento. Roma: Bulzoni.

VARGAS LLOSA, M. (2003). Literatura y política. Atenas: Instituto Cervantes.

TIVALDI CHIESA, M. (1970). Letteratura infantile. Milano: Garzanti. 